\title{
Lessons Learned and Future Challenges
}

\author{
Christian Henning and Ousmane Badiane
}

"Until we understand why our society adopts its policies, we
will be poorly equipped to give useful advice on how to
change those policies."
George J. Stigler in "The Citizen and the State." Chicago:
University of Chicago Press, p. ix, 1975

This book started with the key challenges for African leaders endorsing the Comprehensive Africa Agriculture Development Programme (CAADP) to make CAADP work. These challenges include at least two aspects. First, to identify, among the programs that do work, those that provide the best value for money. Second, to achieve political feasibility (i.e. to effectively implement identified evidence-based policies). These challenges are not only relevant for political practitioners, but also imply methodological challenges for scientists for at least two reasons. First, linking economic analysis to policy formulation and outcome is a very complex and tedious process. The problem is not just one of applying rigorous economic theory to high-quality data in order to tackle relevant questions. This is difficult enough but may still be the easiest part. A greater challenge is for the knowledge and insights generated from policy research and analysis to find their way into the decision-making process. And even when it does, science-based evidence forms only one part, and often not the most important part, of the understanding that influences the decision-making process, where imperfect political competition often induces biased incentives for politicians, thereby impeding the implementation of available best-practice politics.

In this context this book examines the methodological challenges to analyze and understand simultaneously both which policies work best and why and how these policies can be effectively implemented given the political and economic

C. Henning $(\bowtie)$

Department of Agricultural Economics, University of Kiel, Kiel, Germany

e-mail: chenning@ae.uni-kiel.de

O. Badiane

International Food Policy Research Institute (IFPRI), Washington, DC, USA

(C) The Author(s) 2018

C. Henning et al. (eds.), Development Policies and Policy Processes in Africa,

Advances in African Economic, Social and Political Development,

DOI 10.1007/978-3-319-60714-6_13 
framework conditions in a country. Overall, the following main results can be summarized from the different contributions to this volume.

\section{Growth-Poverty Linkages}

In line with existing studies (e.g. Diao et al. 2012), the applied CGE modeling approaches highlight the importance of agricultural growth in achieving pro-poor growth in Africa. However, extended linked micro-macro approaches also show that understanding the relative importance of agricultural versus nonagricultural growth also depends on the analysis of economic interlinkages between poor households and the agricultural and nonagricultural sectors. These linkages can be rather complex. In particular, they include household labor market responses to economic shocks as well as nutrition-growth-poverty linkages. Moreover, analyzing public investments that promote technical progress to achieve poverty reduction reveals that agricultural subsectors are key, because investments promoting t.p. in these subsectors are comparatively productive, while vice versa many nonagricultural sectors are characterized by a high potential for achieving pro-poor growth (i.e. assuming exogenous growth for these sectors implies a high impact on poverty reduction) but the investment required to achieve growth is much higher when compared to investments in agriculture. Nevertheless, analyses imply that the classical agriculture-nonagriculture nexus is too simple (i.e. an efficient pro-poor growth [PPG] strategy needs to target specific agricultural and nonagricultural sectors).

\section{Policy-Growth Linkages}

Promoting pro-poor growth in Africa demands public investment. In particular, to achieve the Millennium Development Goals, public investment in agriculture needs to be significantly increased in almost all African states analyzed in this book, though to different degrees. However, beyond total public investments in agriculture the composition of the agricultural budget is also crucial to guarantee an optimal investment strategy. The latter applies not only to the allocation of budget resources across agricultural and nonagricultural policy programs, but also to the allocation of resources across different CAADP policy programs. For example, microeconometric analyses undertaken for Uganda highlight the importance of agricultural extension services. Furthermore, extended econometric approaches undertaken for Malawi reveal that optimal composition of public investments crucially depend on specific policy-growth and growth-policy linkages, which are country specific. Accordingly, it is impossible to identify a set of key policies that fits all African countries, but rather each country needs to identify its own optimal PPG strategy. Thus, while a focus on investment in agricultural extension may work 
for Uganda, making CAADP work in Malawi requires major investments in rural infrastructure as well as in water and land management. Beyond the identification of optimal pro-poor growth strategies, the understanding of the political processes involved in formulating and implementing these policies is essential.

\section{Incentives Versus Knowledge Gaps}

Based on analyses undertaken in this book, political decision-making regarding public investment in agriculture and nonagriculture are determined by three components: first, political incentives of governments to invest and second, political knowledge regarding the impact of different policies on growth and poverty reduction. Thirdly, beyond incentives and knowledge realized, PPG strategies also depend on financial resources available to national governments. Accordingly, the persisting inefficient policies observed in many African countries is the result of a lack of both adequate incentives and political knowledge and also lack of sufficient financial resources. In contrast to existing political economy studies mainly focusing on incentive gaps, e.g. biased incentives in favor of special interests at the expense of the poor, the application of a CGPE approach to the CAADP reform process in Malawi implies that inefficient policies mainly result from knowledge gaps, while biased incentives play only a minor role. In particular, at least in the Malawi case, adequate political knowledge does not presently exist either in the political system or the science sector, but must be generated in a dynamic policy learning process.

\section{Stakeholders Play an Important Role in Participatory Policy Processes Determining Governmental Performance}

Stakeholders influence governmental incentives to invest in specific programs and sectors via lobbying. Moreover, stakeholders also impact final policy decisions via influencing the political beliefs of politicians (i.e. their applied political knowledge). Politicians apply policy beliefs (i.e. simple mental models) to understand the impact of different policies on poverty and growth, where politicians update their beliefs via communication learning through policy networks. Especially, national research and international donor organizations take a central position in political communication networks and hence exert a strong influence on the final policy beliefs of powerful politicians. In contrast, private interest groups (e.g. farm organizations), which are not as central to political communication networks, influence the political incentives of governments to invest in specific CAADP policy programs mainly via lobbying. 
However, given the fact that none of involved stakeholder and governmental organizations cumulates the total political knowledge (i.e. perfectly understands which specific combination of policies works best for Malawi), shifting political power to the research, donor or national stakeholders would not imply more efficient or effective policy outcomes. What is needed to find practical solutions is an institutionalized communication process that allows for a productive combination of individual knowledge among stakeholders via an interactive exchange of ideas especially among political practitioners and scientific researchers.

\section{Voter Behavior Is Another Important Determinant of Governmental Performance}

Closing the knowledge gap is a necessary but not sufficient condition to make CAADP work. However, given the fact that most African states nowadays are truly democratic, the political feasibility of development policies depends on the electoral responses of the voters. Hence, any comprehensive understanding of the political economy of major policy reforms like CAADP has to take into account the electoral responses of different social groups.

In this book we show that understanding how voter behavior impacts governmental incentives means understanding how voters cast their votes. Analyzing voter behavior (i.e. electoral responses to governmental policies and induced policy outcomes) implies that electoral responses of voters to governmental policies are determined by the relative importance of non-policy oriented voting motives in comparison to policy-oriented voting motives. The more voters base their votes on non-policy issues, the more they can be influenced by campaigning. Hence, elected politicians have high incentives to deliver policies that serve the interests of influential interest groups (i.e., the latter are influential in the sense that they control the voting behavior of their clientele). Hence, governmental policy is highly influenced by the lobbying activities of special interest groups. However, if voters engage in retrospective voting (i.e. base their votes on observed economic performance), the government has a high incentive to deliver good policies (i.e. policies that really work and serve the public interest). As a corollary, retrospective voting implies a high incentive for governments to engage in policy learning. Finally, beyond non-policy oriented voting, voters engage in policy-oriented voting (i.e. they base their evaluation of parties competing in election on party platforms). Policy-oriented voting implies an incentive for elected politicians to deliver policies desired by a majority of voters. However, policy-oriented voting does not necessarily imply efficient policy outcomes. To the contrary, compared to politicians and stakeholders, the average voter is a layman when it comes to development policies like CAADP. Accordingly, policy positions preferred by voters are based on naïve beliefs about how different policies work and therefore can be extremely inefficient. Nevertheless, in political reality the more voters base their votes on non-policy issues, the less is their joint political weight vis-a-vis organized interest groups in determining governmental 
policy choices. Moreover, to the extent that the relative importance of non-policy voting varies systematically across social groups (e.g. poor versus rich), the relative political weights of social groups also differ. Hence, government capture basically results from the relative importance of non-policy voting.

Empirical analyses of voter behavior undertaken for Malawi implies that the electoral choices of Malawian voters are mainly driven by non-policy issues with an average importance of $66 \%$ followed by policy-oriented voting with an average importance of $30 \%$. Very little importance resulted for retrospective voting with an average importance of only $4 \%$. Therefore, governmental incentives are mainly oriented towards interest groups with a total weight of $60 \%$ compared to only $40 \%$ for the total voter population. However, voter behavior varies systematically across social groups implying different relative political weights across voters. Interestingly, empirical estimations imply that the Malawian government is less captured by rich versus poor or rural versus urban populations, but rather by specific regional and ethnic groups. In particular, the North is significantly underrepresented, while the Chewa and Yao tribes as well as the central region seem to be politically overrepresented.

Nevertheless, based on our empirical results, the political feasibility of CAADP options in Malawi still significantly depends on voters' choices given the fact that policy-oriented voting counts for $40 \%$ of voters' electoral responses. Our results clearly imply that the less voters rely on non-policy indicators and the more they base their electoral choices on party policy platforms and evaluate the competence of the government based on observed economic development, the more electoral competition induces incentives for the government to implement policies that correspond to the policy preferences of the majority of the society.

However, our analyses also reveal that a high political representation of voters' policy preferences by the government does not necessarily imply that the government implements the most efficient policies. The latter conclusion results from the fact that voters' policy preferences might be biased. Interestingly, taking biased voter beliefs into account, a high importance of lobbying in combination with governmental leadership that is driven by its own intrinsic political vision might induce more efficient policy choices while simultaneously decreasing governmental performance, as defined in terms of capture and accountability. The highly recognized work of Caplan draws the rather pessimistic conclusion that democratic mechanisms of preference aggregation naturally lead to the choice of inefficient policies. Hence, the analysis of voter beliefs is an important topic of our future research.

\section{Donor Funding Can Contribute to Ensuring the Political Feasibility of Efficient Pro-Poor Growth Strategies}

Promoting pro-poor economic growth strategies in the future requires investments today. These investment have to be financed. Ensuring there is sufficient funding is a major concern in most African countries (see Benin and Yu 2012). In Malawi, as in most African countries, a large share of financial resources used for project funding is 
provided by development partners. If donors neglect their commitments, funding by the government only would result in far lower allocation of the total budget to policy programs promoting growth in both agriculture and nonagriculture. In contrast, the large part of the state budget is spent on the provision of public good services such as social and health services. Naturally, the latter has strong political implications. Thus, donors play a key role in determining political feasibility of an optimal PPG strategy, since governmental incentives for public investment are crucially determined by external funds provided by donors.

\section{From Political Diagnosis to Therapy}

If policy failure is dominated by knowledge gaps, while biased political incentives have only minor importance, formal political institutions (e.g. constitutional rules like electoral rules or legislative procedures) have little impact on political performance. By the same argument, a simple increase in the political influence of any stakeholder organization will also be ineffective. Furthermore, if neither the policy beliefs of policymakers nor the parameter specifications of scientific models correspond to the true political technology, adequate political knowledge does not yet exist neither in the scientific system nor in political praxis and thus must be created in the political process. Designing effective observational policy learning is facilitated by an effective monitoring and evaluation system. However, even with an appropriate $M \& E$ system, observational learning often takes a long time and hence is extremely costly. Therefore, beyond observational learning, communication learning is also important. The latter requires an interactive exchange between scientific modelers, politicians and stakeholders. To facilitate this exchange, innovative communication tools, such as computer-based policy toolkits like CAADP-lab, or participatory policy processes including politicians and stakeholders as well as research and donor organizations are required.

\section{Innovative Methodological Approaches}

The challenge of empirically analyzing and designing participatory and evidencebased policy processes is the development of an applicable model framework that first enables a comprehensive political diagnosis (i.e., the identification of the principal source of low political performance in terms of incentives and knowledge gaps). Such a framework should then enable the derivation of an effective political therapy (i.e., provide tools that allow the identification of adequate strategies for reducing existing political performance gaps). The derivation of a political therapy requires quantitative modeling of the political decision-making and policy learning processes, including the endogenous formation of legislators' political preferences and policy beliefs (i.e., agents' simplified mental models for approximating the complex true relationship between policy instruments and induced policy outcomes). 
Facing these methodological challenges this book develops and applies a CGPE model as a new quantitative approach to analyzing the performance of policy processes with respect to the production of efficient policy choices. In contrast to existing political economy models, which highlight the biased incentives of politicians as a principal cause of persisting inefficient policies, the CGPE approach incorporates explicitly the lack of adequate political knowledge as another important source of inefficient policy choices. Within the CGPE approach, a model of political belief formation and updating explains how political agents organized a combination of observational and communication learning processes in networks to improve their political knowledge. According to the CGPE model, the main determinants of the accumulation of political knowledge and the speed of policy learning correspond to policy network structures that reflect the communication and interaction patterns between governmental and nongovernmental organizations. Moreover, in principal a voter module can be incorporated in the CGPE approach allowing the calculation of political feasibility indices for given policy options. Beyond efficiency, political feasibility is another important aspect of evaluating policy options that work in political praxis.

\section{Future Outlook and Challenges}

Although we think that the work presented in this book makes a significant contribution to the modeling and evaluation of policies and political processes, it clearly has limitations which should be tackled in future work.

First, economic modeling is still rather restrictive, e.g. labor market restrictions as well as price volatility, weather shocks and other exogenous shocks including farmers' risk perception are still excluded from applied economic models. Another important aspects that should be included in future work is the interrelations of agriculture production and sustainability.

Second, although the PIF approach is certainly an improvement in modeling policy-growth linkages, present approaches are still limited. By construction, we assume that budget spending for a specific policy program $\left(\gamma_{\mathrm{i}}\right)$ is homogenously effective in promoting t.p. in different subsectors. However, in reality, it appears more realistic that even within specific policy programs (e.g., investments in infrastructure), different subprograms can be formulated by focusing on specific subsectors. For example, investing in the infrastructure of specific regions or investing in the railroad system versus the road system might be more or less effective for different subsectors. These differences occur because subsectors might be regionally concentrated or dependent on specific infrastructure systems. Thus, including a third stage in our PIF function that allows for sector-specific subprograms within a specific policy program corresponds to a potential extension of the PIF to deal with subsector specific effectiveness of policy programs.

Moreover, the presented PIF function does not explicitly allow the assessment of implementation efficiency. Evaluation of specific budget allocations across different policy programs depends on how programs are finally implemented. For 
example, investment in rural road infrastructure via building fancy roads to remote villages where no real business exists to take advantage of these roads would not have a real impact on growth. Moreover, buying cars for extension officers who have low capacities to advise farmers would also not make a big contribution to promoting farm productivity. A possible extension of the PIF approach taking implementation efficiency into account would be to incorporate a third or fourth stage corresponding to different implementation mechanisms that determine effective budget uses under various subprograms in the second or third stage.

Regarding political economy modeling, the following aspects are limitations of the current CGPE approach:

First, in its present version, the CGPE does not yet incorporate the voter module (i.e., political support functions are derived exogenously from interview data). Basically, this setup implies that political support is driven by retrospective and non-policy voting only, while policy-oriented voting is neglected. However, as demonstrated in Chapter "Voter Behavior and Government Performance in Malawi: An Application of a Probabilistic Voting Model", policy-oriented voting is an important determinant of voter behavior. Hence, voters' policy beliefs might effectively restrict politicians' policy choices. This aspect is not fully reflected in the presented CGPE analyses. Thus, incorporating the voter module and deriving political support endogenously from estimated voter behavior might imply that observed political performance is actually more restricted by biased political incentives than implied by the presented CGPE analyses. Furthermore, understanding how voters update their policy beliefs within public opinion formation (e.g. what is the role of mass media versus political campaigning and stakeholder communication within this process) is a very important and interesting aspect that needs to be analyzed in future research.

Second, although it has been demonstrated by applying the CGPE approach that interactive communication among politicians, stakeholders and researchers is important for effective policy learning, the concrete institutional organization of such interactive communication has not been analyzed yet. Thus, this is another important aspect we leave for future research.

\section{References}

Benin, S., and B.X. Yu. 2012. Complying the Maputo declaration target: Trends in public agricultural expenditures and implications for pursuit of optimal allocation of public agricultural spending. ReSAKSS Annual Trends and Outlook Report 2012.

Diao, X., J. Thurlow, S. Benin, and S. Fan, eds. 2012. Strategies and Priorities for African Agriculture: Economywide Perspectives from Country Studies. Washington, DC: International Food Policy Research Institute (IFPRI). 
Christian Henning is professor and chair of agricultural economics, University of Kiel (Germany). He studied economics, agricultural economics, sociology, political science and mathematics. He earned a PhD in economics, in agricultural economics and in political science. His main areas of specialization are applied political economy and applied economic modelling of agricultural policies. To date he has published five books and various articles in refereed journals including PLoS ONE, American Journal of Agricultural Economics, European Review of Agricultural Economics, Journal of Public Policy, Journal of Mathematical Sociology and Journal of Theoretical Politics.

Ousmane Badiane is the Director for Africa at the International Food Policy Research Institute (IFPRI), based in Washington, D.C. He oversees the Institute's regional offices for West and Central Africa, in Dakar, Senegal, and Eastern and Southern Africa, in Addis Ababa, Ethiopia. He received a Master's Degree and $\mathrm{PhD}$ in agricultural economics from the University of Kiel in Germany. His awards include being selcted as a 2015 Yara Prize Laureate, a Doctoral Degree Honoris Causa from the University of KwaZulu Natal in South Africa and induction as Distinguished Fellow of the African Association of Agricultural Economics.

Open Access This chapter is licensed under the terms of the Creative Commons Attribution 4.0 International License (http://creativecommons.org/licenses/by/4.0/), which permits use, sharing, adaptation, distribution and reproduction in any medium or format, as long as you give appropriate credit to the original author(s) and the source, provide a link to the Creative Commons license and indicate if changes were made.

The images or other third party material in this chapter are included in the chapter's Creative Commons license, unless indicated otherwise in a credit line to the material. If material is not included in the chapter's Creative Commons license and your intended use is not permitted by statutory regulation or exceeds the permitted use, you will need to obtain permission directly from the copyright holder.

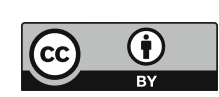

